\title{
Optical and structural properties of ZnO films deposited on GaAs by pulsed laser deposition
}

\author{
Y. R. Ryu $u^{\text {a) }}$ and S. Zhu ${ }^{\text {b) }}$ \\ Department of Physics and Astronomy, University of Missouri-Columbia, Columbia, Missouri 65211 \\ J. D. Budai \\ Solid State Division, Oak Ridge National Laboratory, Oak Ridge, Tennessee 37831 \\ H. R. Chandrasekhar, P. F. Miceli, and H. W. White \\ Department of Physics and Astronomy, University of Missouri-Columbia, Columbia, Missouri 65211
}

(Received 10 December 1999; accepted for publication 23 March 2000)

\begin{abstract}
$\mathrm{ZnO}$ films were synthesized on GaAs substrates at different growth conditions by pulse laser deposition. High-purity (99.999\%) oxygen was used as the ambient gas. The pressure of the ambient oxygen gas for $\mathrm{ZnO}$ film growth was varied from 20 to $50 \mathrm{mTorr}$, and the growth temperature from 300 to $450{ }^{\circ} \mathrm{C}$. $\mathrm{ZnO}$ films showed very strong bound exciton peaks located between 3.37 and 3.35 $\mathrm{eV}$. The full width at half maximum of the bound exciton peak is less than $5 \mathrm{meV}$. These results indicate $\mathrm{ZnO}$ films on GaAs substrates can be used for optical devices such as light-emitting diodes. The other significant properties of textured $\mathrm{ZnO}$ films on GaAs substrates are described. (C) 2000 American Institute of Physics. [S0021-8979(00)02013-2]
\end{abstract}

\section{INTRODUCTION}

$\mathrm{ZnO}$ films have been studied extensively for use in piezoelectric and waveguide devices. Recently, $\mathrm{ZnO}$ films have become attractive candidates as substrates for $\mathrm{GaN}$ films because both materials possess the same crystal structure (wurtzite) with small lattice mismatch. GaN is known as a good material for fabrication of optical devices such as blue light emitting diodes (LEDs) and blue laser diodes (LDs). Nakamura has used GaN in an effort to increase the average lifetime of blue LDs toward a goal of $10000 \mathrm{~h}$ at room temperature. ${ }^{1}$

This research was motivated by the possibility that $\mathrm{ZnO}$ could be a good candidate material for optical devices such as blue LEDs. This supposition is based on the fact that the crystal structure of $\mathrm{ZnO}$ is the same as that of $\mathrm{GaN}$, and that the optical properties are similar to each other. ${ }^{2} \mathrm{ZnO}$ has other physical features that make it attractive. For example, as a wide band-gap semiconductor, $\mathrm{ZnO}$ is a relatively hard material. The strength of the $\mathrm{Zn}-$ to-O bond is larger than that of the Ga-to-N bond. Their difference in bonding strength can lead to significantly different results for $p$-type doping. $\mathrm{ZnO}$ has a melting temperature of about $2000^{\circ} \mathrm{C}$. Thus, $\mathrm{ZnO}$ is sufficiently stable that it can withstand the high temperature annealing and treatment processes associated with doping and forming ohmic contacts. The hardness of $\mathrm{ZnO}$, its resistance to mechanical stress, and its high melting temperature are features that could conceivably expand the lifetime of devices such as blue LEDs and blue LDs fabricated with this material, and for some applications it is possible that $\mathrm{ZnO}$ could be superior to $\mathrm{GaN}$.

\footnotetext{
a) Author to whom correspondence should be addressed; electronic mail: ryuy@missouri.edu

${ }^{b}$ Present address: Universities Space Research Association, NASA/MSFCHuntsville, AL 35803.
}

It was very difficult to make $p$-type GaN material. ${ }^{3}$ However, $p$-type $\mathrm{ZnO}$ films can be obtained without any processing steps after $p$-type film growth. We have successfully grown $p$-type $\mathrm{ZnO}$ on $\mathrm{GaAs}$, for which detailed information will be presented in a separate article. ${ }^{4}$ Another attractive property of $\mathrm{ZnO}$ films is that highly $c$-axis oriented, selftextured $\mathrm{ZnO}$ films can be synthesized on any semiconductor substrate, such as $\mathrm{Si}$ and GaAs, although it was an epitaxial $\mathrm{ZnO}$ film grown on a single crystal (0001)-sapphire substrate that was earlier reported. ${ }^{5}$ It is interesting to study the crystal structure and optical properties of textured $\mathrm{ZnO}$ films because high-quality self-textured $\mathrm{ZnO}$ films can be synthesized on any substrate, and these $\mathrm{ZnO}$ films may give an important contribution to the production of optoelectronic devices.

The pulsed laser deposition (PLD) technique has been used to grow thin films for a broad range of materials. Further, the PLD method is very unique for growth of oxide materials because the oxygen plasma created by the pulsed laser is very energetic and its density is easily controllable by changing the oxygen pressure. For these practical reasons, $\mathrm{ZnO}$ films have been synthesized by PLD, ${ }^{5,6}$

In this article we report the deposition of high quality $\mathrm{ZnO}$ films on (001)-GaAs substrates using PLD. The crystalline and optical properties of $\mathrm{ZnO}$ were studied as a function of growth temperature and ambient oxygen gas pressure.

\section{FILM GROWTH}

$\mathrm{ZnO}$ films were synthesized on (001)-GaAs substrates by PLD using an ArF excimer laser. Experiments were performed in a high-vacuum chamber maintained at $8 \times 10^{-7}$ Torr by a turbopump. The focused laser radiation illuminated a rotating $\mathrm{ZnO}$ target at an incident angle of $40^{\circ}$. The target was $99.999 \%$ pure polycrystalline $\mathrm{ZnO}$. The target-tosubstrate distance was $7 \mathrm{~cm}$. 


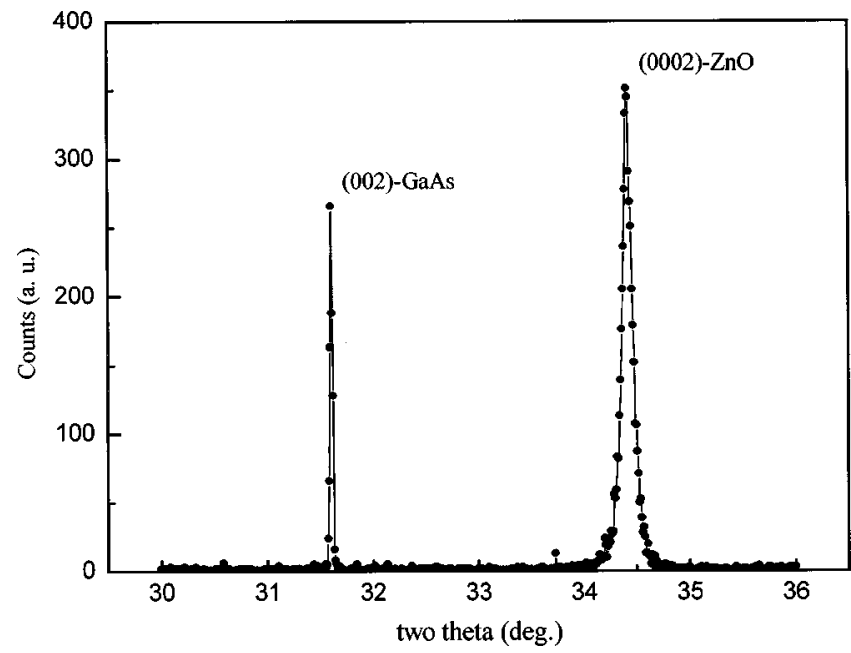

FIG. 1. The x-ray $\theta-2 \theta$ rocking curve for a $\mathrm{ZnO}$ film on GaAs. A (0002)$\mathrm{ZnO}$ peak indicates the $\mathrm{c}$-axis oriented growth direction.

As received, epitaxial-ready GaAs substrates were not treated with any chemical cleaning process before being loaded into the chamber. Prior to film growth they were cleaned by a hydrogen-electron-laser process in Ref. 7, for $20 \min$ at $480^{\circ} \mathrm{C}$.

$\mathrm{ZnO}$ films were synthesized at $300,350,400$, and 450 ${ }^{\circ} \mathrm{C}$ under an ambient gas pressure of $35 \mathrm{mTorr}$ of high-purity oxygen (99.999\%). $\mathrm{ZnO}$ films were also grown at $350^{\circ} \mathrm{C}$ at different ambient pressures of 20,35, and 50 mTorr of oxygen gas to observe the effect of ambient gas pressure on crystal structure and morphology. $\mathrm{ZnO}$ films were grown immediately after the target had been preablated. The growth chamber was filled with argon gas at the time laser illumination was begun to create a $(\mathrm{Zn}, \mathrm{O})$ plasma. The use of an ambient gas of sufficient pressure helps avoid particulate deposition on the film. ${ }^{7}$ Keeping a designated ambient gas pressure, argon gas was gradually replaced with oxygen gas while maintaining laser illumination of the target. The laser repetition rate was $20 \mathrm{~Hz}$ and the power per pulse was $80 \mathrm{~mJ}$. The energy density of the focused laser beam was roughly estimated to be $2 \mathrm{~J} / \mathrm{cm}^{2}$ at the target. The thicknesses of the $\mathrm{ZnO}$ films were in the range $0.7-1.1 \mu \mathrm{m}$.

\section{MEASUREMENTS AND RESULTS}

$\mathrm{ZnO}$ films were measured by XRD to study crystal structure. The x-ray $\theta-2 \theta$ rocking curve for a $\mathrm{ZnO}$ film on $\mathrm{GaAs}$ is shown in Fig. 1. The strong intensity of the (0002)- $\mathrm{ZnO}$ peak indicates a self-texture preference in the $c$-axis direction, even on a GaAs substrate. X-ray in-plane measurements show that $\mathrm{ZnO}$ films deposited by PLD have hexagonal structures. Figure 2 shows the variation of the full width at half maximum (FWHM) of the x-ray $\theta$-rocking curve for the (0002)-ZnO peak with oxygen gas pressure and the substrate temperature. The results can be understood by considering the $(\mathrm{Zn}, \mathrm{O})$ plume size, the reactive oxygen density, the density of particulates generated at the target that reach the substrate, the surface mobility, and As diffusion into the newly formed $\mathrm{ZnO}$ layers. Oxygen ambient molecules can be transformed into reactive elements through inelastic collisions

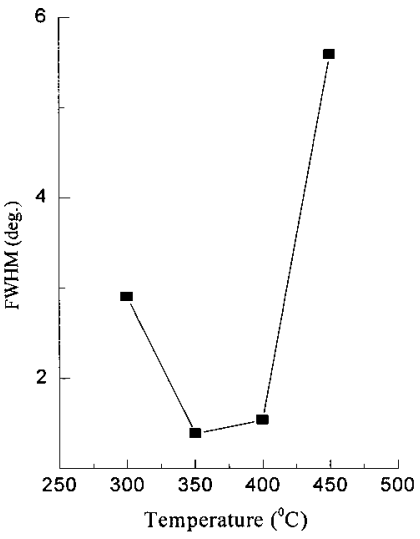

(a)

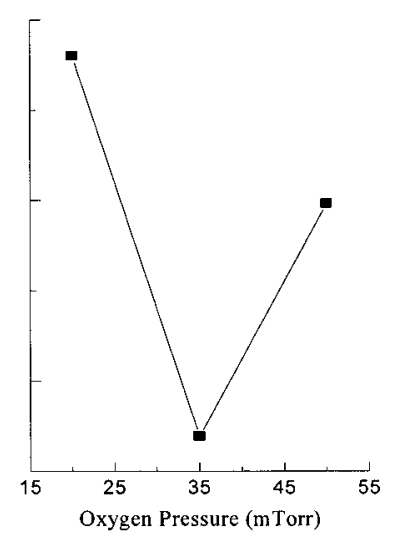

(b)
FIG. 2. (a) and (b) show the effects of growth temperature and oxygen gas pressure on the crystalline quality of $\mathrm{ZnO}$ film grown by PLD. The FWHM values of the x-ray $\theta$ rocking curves are for the (0002)- $\mathrm{ZnO}$ peaks. The pressure of an ambient oxygen gas was fixed at $35 \mathrm{mT}$ Torr for (a) and the substrate temperature was fixed at $350{ }^{\circ} \mathrm{C}$ for (b). The best $\mathrm{ZnO}$ film was synthesized at $350^{\circ} \mathrm{C}$ and 35 mTorr, with a FWHM value of $1.39^{\circ}$ for the $\theta$ rocking curve.

within the initial $(\mathrm{Zn}, \mathrm{O})$ plasma that is created from the $\mathrm{ZnO}$ target by the focused laser beam. $\mathrm{ZnO}$ films, regardless of the growth technique used, possess some oxygen vacancies. Thus, it is very important for $\mathrm{ZnO}$ film growth that the amount of available reactive oxygen created from the ambient oxygen gas be sufficient to help reduce the number of oxygen vacancies. It is also known that the number of particulates arriving at the substrate is decreased as the pressure of an ambient gas increases. ${ }^{7,8}$ Deposited particulates in a $\mathrm{ZnO}$ film degrade film quality. For these reasons, generally speaking, the crystal quality is improved as the ambient gas pressure increases.

At sufficiently high ambient gas pressures, however, the $(\mathrm{Zn}, \mathrm{O})$ plasma will not reach the substrate and the $\mathrm{ZnO}$ film will not be well crystallized. The plasma density that might be expected from a Beer's law behavior is given by $I$ $=I_{0} \exp -P \sigma x$, where $I_{0}, P, \sigma$, and $x$ are the initial plasma density at the target, the oxygen ambient gas pressure, the total cross section for plasma-to-oxygen collisions, and the distance from the target, respectively. ${ }^{9}$ The density of available source elements for $\mathrm{ZnO}$ film growth might be exponentially decreased as the ambient gas pressure increases, and the relative density ratio for the $\mathrm{Zn}$ and $\mathrm{O}$ elements may not be good for high-quality film growth at a high ambient pressure such as 50 mTorr. ${ }^{10}$ The plume size $(R)$ is related to the ambient gas pressure and to the laser-pulse energy $(E)$. It can be roughly calculated by $R \propto(E / P)^{1 / 3 \gamma}$, where $\gamma$ is the ratio of specific heats of the elements in the plume. ${ }^{11}$ If the substrate is located beyond the plume size $R$, the adhesion coefficient for source elements that arrive at the substrate is drastically decreased. Therefore, the crystal quality of $\mathrm{ZnO}$ becomes worse as the ambient gas pressure increases beyond an optimal pressure. The ambient oxygen gas pressure should be neither too low nor too high. An acceptable value is 35 mTorr for $\mathrm{ZnO}$ film growth on GaAs.

Arsenic atoms from the GaAs substrate can evaporate 

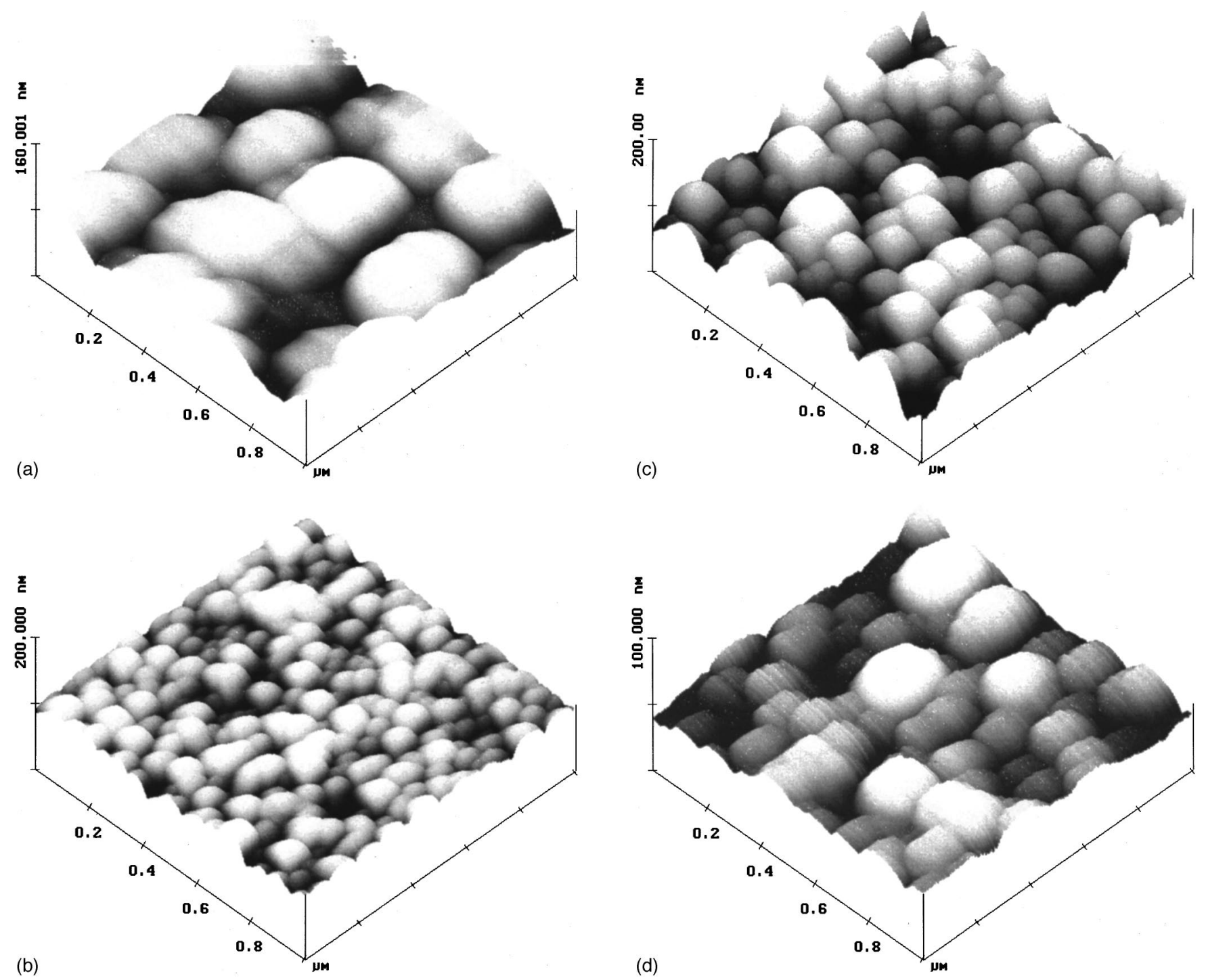

FIG. 3. AFM images of the $\mathrm{ZnO}$ films deposited by PLD. (a), (b), (c), and (d) are for $\mathrm{ZnO}$ samples grown at temperatures of $300,350,400$, and $450{ }^{\circ} \mathrm{C}$, respectively. The scanned area is $1 \times 1 \mu \mathrm{m}^{2}$. The surface roughness for each is respectively 7.4, 9.4, 17.1, and $5.9 \mathrm{~nm}$, proceeding from (a) to (d). The grain sizes of samples grown at 300 and $450{ }^{\circ} \mathrm{C}$ are larger than those of samples grown at 350 and $400{ }^{\circ} \mathrm{C}$.

and diffuse into the $\mathrm{ZnO}$ layers at a sufficiently high substrate temperature, such as $450^{\circ} \mathrm{C}$. Therefore high substrate temperatures are to be avoided for ultrapure $\mathrm{ZnO}$ film growth on GaAs substrates, unlike that for $\mathrm{ZnO}$ film growth on sapphire substrates. On the other hand, the surface mobility for $(\mathrm{Zn}, \mathrm{O})$ elements at the substrate may be too low for highquality film growth at low temperatures such as $300^{\circ} \mathrm{C}$.

Even though these interpretations require further study, these relations are implicitly indicated by the results in Fig. 2. The best films, with a FWHM value of $1.39^{\circ}$, were synthesized with growth parameters of $350^{\circ} \mathrm{C}$ substrate temperature and 35 mTorr ambient oxygen gas pressure.

Film surface morphologies were studied using atomic force microscopy (AFM) measurements. AFM measurements were performed in air using a model Nanoscope IIIa SPM manufactured by Digital Instruments, Inc. All samples were scanned over areas ranging from $500 \times 500 \mathrm{~nm}^{2}$ to 10 $\times 10 \mu \mathrm{m}^{2}$, and at several different locations on the film surface. $\mathrm{ZnO}$ films synthesized in an ambient pressure of 20
mTorr oxygen showed a few particulates, with a density of about $1 / \mu \mathrm{m}^{2}$. It was very difficult to find any particulates in $\mathrm{ZnO}$ films grown at ambient gas pressures higher than 20 mTorr, which is a consistent result with those for $\mathrm{ZnSe}$ film growth. ${ }^{7}$ For growth at $350{ }^{\circ} \mathrm{C}$, with increased ambient gas pressure, the surface became smoother, and the microcrystalline (grain) size became smaller.

Surface morphologies vary significantly among $\mathrm{ZnO}$ films grown at different temperatures. Figure 3 shows AFM images from those samples grown at different temperatures but at the same ambient pressure, 35 mTorr of oxygen. They show the effect of growth temperature on film morphology. In particular, surface roughness and grain size are much different. The $\mathrm{ZnO}$ films grown at $350{ }^{\circ} \mathrm{C}$ show an average roughness of $9.4 \mathrm{~nm}$ (root-mean-square) within the scanned area, $1 \times 1 \mu \mathrm{m}^{2}$. Their grain sizes are the smallest, though the samples at $450{ }^{\circ} \mathrm{C}$ did have the smoothest surfaces. The grain sizes in all samples ranged from 40 to $300 \mathrm{~nm}$. The 


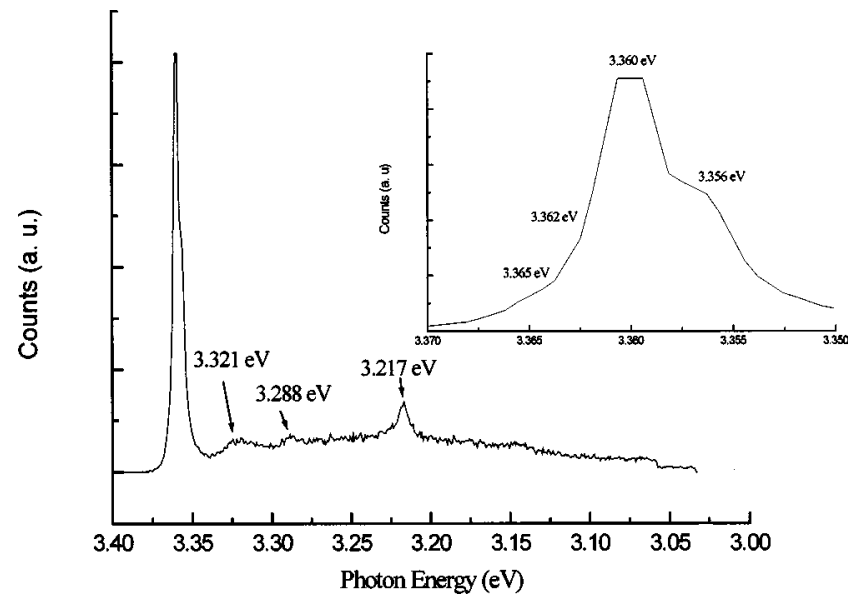

FIG. 4. PL spectra measured at $20 \mathrm{~K}$ obtained with a $\mathrm{cw}$ argon ion laser for a $\mathrm{ZnO}$ sample synthesized at a substrate temperature of $350{ }^{\circ} \mathrm{C}$. The inset shows at least three different peaks in the photon energy range 3.35-3.37 eV.

growth modes are probably different at different temperatures due to the influence of the substrate.

The optical properties of $\mathrm{ZnO}$ films were characterized at $20 \mathrm{~K}$ by photoluminescence (PL) spectroscopy. They were excited with an argon ion laser operating at $351.1 \mathrm{~nm}$ wavelength. As shown in Fig. 4, the PL spectra for a $\mathrm{ZnO}$ film grown at $350{ }^{\circ} \mathrm{C}$ and 35 mTorr oxygen are characterized by significant spectral peaks located at 3.360, 3.356, 3.321, 3.288 , and $3.217 \mathrm{eV}$. The dominant and narrow peaks located at 3.360 and $3.356 \mathrm{eV}$ are the near band-edge (NBE) emissions of excitons bound to donors $(D X)$, which are consistent with the results reported previously. ${ }^{12,13}$ The FWHM values of each peak are less than $5 \mathrm{meV}$. The peaks located at $3.321 \mathrm{eV}$ are identified as the NBE emissions of excitons bound to acceptors $(A X)$ as determined from systematic measurements on $p$-type $\mathrm{ZnO}$ films, described elsewhere. ${ }^{4}$ The peak located at $3.288 \mathrm{eV}$ might be identified as an LO phonon replica. ${ }^{13}$ Other interesting peaks at 3.217 may be due to donor-acceptor pair transitions. For undoped $\mathrm{ZnO}$ films it is reasonable that the intensity of the $D X \mathrm{NBE}$ emission is stronger than that of the $A X \mathrm{NBE}$ emission because they are intrinsic $n$ type due to the presence of oxygen deficiencies. On the other hand, there are additional broad peaks located at about 2.8 and $2.1 \mathrm{eV}$ (not shown) which could conceivably be deep level emissions. The intensity of the peaks located at about $2.8 \mathrm{eV}$ is very weak, and the intensity of the peaks at about $2.1 \mathrm{eV}$ are comparable to the intensity of the $D X \mathrm{NBE}$ emission. For these $\mathrm{ZnO}$ films grown by PLD it was very difficult to detect any spectral peak contributions located at about $2.4 \mathrm{eV}$, the so-called green band; ${ }^{2}$ however, such contributions are sometimes (but not always) very strong for $\mathrm{ZnO}$ grown by the hydrothermal growth technique. The presence of the green band might possibly be correlated with deep levels created by hydrogen atoms. Such a correlation would explain why $\mathrm{ZnO}$ grown by PLD without use of hydrogen shows very weak peaks in the green band. These results indicate that further study is required to fully understand the optical properties of $\mathrm{ZnO}$. NBE emissions from $D X$ centers located at 3.360 and $3.356 \mathrm{eV}$ can be separated into at least two peaks for each emission, as shown in Fig. 4. ${ }^{12}$ The peak at $3.365 \mathrm{eV}$ might be the $A$ band free exciton emission. $^{12}$

Based on the fact that FWHM values from x-ray $\theta$ rocking curves are greater than $1^{\circ}$, it is rather surprising that the $\mathrm{ZnO}$ films in this study show very strong excitonic peaks in their PL spectra. The quality of the crystalline structure of a $\mathrm{ZnO}$ film on GaAs is less than, and not even comparable with, that of GaN on sapphire; however, a $\mathrm{ZnO}$ film shows very narrow and very strong excitonic peaks, being comparable with those observed for GaN. These particular features of $\mathrm{ZnO}$ may be the evidence that a $\mathrm{ZnO}$ film possesses high light radiation efficiency.

\section{CONCLUSION}

$\mathrm{ZnO}$ films were synthesized on GaAs by PLD. Results from this work demonstrate that the PLD technique is a good method for growth of $\mathrm{ZnO}$ films. The grain size and the surface morphology of a $\mathrm{ZnO}$ film could be controlled by proper adjustment of the oxygen gas ambient pressure and the substrate temperature during growth. It is remarkable that $\mathrm{ZnO}$ films show very strong excitonic emission peaks, although the FWHM values of the x-ray $\theta$ rocking curves for their (0002)- $\mathrm{ZnO}$ peaks are much larger than $1^{\circ}$. A reasonable interpretation of the XRD and PL results supports the possibility that $\mathrm{ZnO}$ has a radiation efficiency value at least comparable to that of $\mathrm{ZnSe}$ or GaN. These properties make $\mathrm{ZnO}$ a plausible candidate material for short-wavelength visible or UV LEDs.

\section{ACKNOWLEDGMENTS}

This work was supported in part by University of Missouri Research Board under Grant No. RB95-061, the U.S. Army Research Office (Research Triangle Park, N.C.) under Grant No. DAAH04-94-G-0305, and the Office of Naval Research-Electronics Division, Contract No. N00014-99-10288 .

${ }^{1}$ S. Nakamura, INCS'97, Tokushima, Japan, 1997 (unpublished).

${ }^{2}$ D. C. Reynolds, D. C. Look, B. Jogai, and H. Morkoç, Solid State Commun. 101, 643 (1997).

${ }^{3}$ S. Nakamura and G. Fasol, The Blue Laser Diode (Springer, Heidelberg, 1997).

${ }^{4}$ Y. R. Ryu, S. Zhu, D. C. Look, J. Wrobel, H. M. Jeong, and H. W. White, J. Cryst. Growth (submitted).

${ }^{5}$ P. Zu, Z. K. Tang, G. K. L. Wong, M. Kawasaki, A. Ohtomo, H. Koimura, and Y. Segawa, Solid State Commun. 103, 458 (1997).

${ }^{6}$ W. S. Hu, Z. G. Liu, J. Sun, S. N. Zhu, Q. Q. Xu, D. Feng, and Z. M. Ji, J. Phys. Chem. Solids 58, 853 (1997).

${ }^{7}$ Y. R. Ryu, S. Zhu, S. W. Han, and H. W. White, J. Vac. Sci. Technol. A 16, 3058 (1998).

${ }^{8}$ D. B. Chrisey and G. K. Hubler, Pulsed Laser Deposition of Thin Films (Wiley, New York, 1994).

${ }^{9}$ D. B. Geohegan, Laser Ablation: Mechanism and Application (Springer, Heidelberg, 1991).

${ }^{10}$ S. Zhu, Y. Ryu, H. W. White, and Y. Yang, Appl. Surf. Sci. 127/129, 584 (1998).

${ }^{11}$ P. E. Dyer, A. Issa, and P. H. Key, Appl. Phys. Lett. 57, 186 (1990).

${ }^{12}$ D. C. Look, D. C. Reynolds, J. R. Sizelove, R. L. Jones, C. W. Litton, G. Cantwell, and W. C. Harsch, Solid State Commun. 105, 399 (1998).

13 D. M. Bagnall, Y. F. Chen, M. Y. Shen, Z. Zhu, T. Goto, and T. Yao, J. Cryst. Growth 184/185, 605 (1998). 